\title{
La noción de "tecnologías de género" como herramienta conceptual en el estudio del deporte
}

Hortensia Moreno'

\begin{abstract}
Resumen
La idea de "tecnologías de género" aporta una importante herramienta conceptual en el estudio del deporte como ámbito de exclusión, discriminación y segregación de género, pues permite entender no sólo la creación histórica de un coto exclusivo de masculinidad y un sistema de significación donde se definen los valores y las características del mundo sexuado, sino inclusive la producción material de los cuerpos mediante prácticas disciplinarias que realzan y exacerban rasgos distintivos, cuya principal función es representar el género en el seno de la vida social. Las aportaciones de Iris Marion Young, Teresa de Lauretis, Michel Foucault y Erving Goffmann proporcionan un punto de partida decisivo para esta reflexión.
\end{abstract}

Palabras clave: deporte - género - tecnologías del yo - cuerpo - masculinidad.

\begin{abstract}
The notion of "technologies of gender" is an important conceptual tool in the study of sports as realm of gender exclusion, discrimination and segregation. It allows the understanding of the historic creation of an exclusive preserve for the masculinity and a meaning system where values and traits of a sexed world are defined, but even the material production of the bodies with disciplinary practices which enhance and aggravate distinctive features for the representation of gender in social life. The contributions of Iris Marion Young, Teresa de Lauretis, Michel Foucault and Erving Goffman are a crucial standing point for this reflection.
\end{abstract}

Key words: sports - gender - technologies of the self - body - masculinity.

Doctora en Ciencias Sociales con especialidad en Mujer y Relaciones de Género por la Universidad Autónoma Metropolitana. Estudió Periodismo y la maestría en Ciencias de la Comunicación en la Universidad Nacional Autónoma de México. Integra el comité editorial de debate feminista y es académica del Instituto de Investigaciones Sociales y la Facultad de Ciencias Políticas y Sociales de la Universidad Nacional Autónoma de México. 


\section{INTRODUCCIÓN}

¿Por qué las mujeres hacen menos deporte que los hombres? Existen construcciones discursivas considerables donde se legitima esta disparidad desde una mirada normalizante, naturalizadora, esencialista: desde la explicación (utilizada durante el siglo XIX con profusión y detalle) de que la fragilidad consustancial al cuerpo femenino convierte todo ejercicio brusco en un riesgo para su salud, hasta el argumento de la autoselección ("a las mujeres no les gusta el deporte, no cuenta entre sus intereses"), pasando por el peligro de la masculinización y la pérdida de la capacidad reproductiva². Un ejemplo paradigmático lo proporciona Pierre de Coubertin, fundador de los modernos juegos olímpicos, quien aseguró en uno de sus discursos inaugurales (1912) que el deporte femenino era "completamente contra natura" (Fausto-Sterling, 2000: 5).

Sin necesidad de llegar a esos extremos, es fácil constatar que el deporte tiene un componente fundamental de género: la mera inclinación de una niña hacia ese territorio levanta toda clase de dudas acerca de su feminidad ${ }^{3}$. Tales dudas (y su corolario inmediato: la etiquetación de la deportista como una mujer "anormal", es decir, marimacho, lesbiana) cuentan entre los muchos obstáculos (materiales, familiares, educativos, institucionales, religiosos, morales) a los que las mujeres se enfrentan aún hoy, en pleno siglo xxl, si toman la extraña resolución de practicar algún deporte.

\section{Tabla 1 PARTICIPACIÓN DE MUJERES EN LOS JUEGOS OLÍMPICOS DE VERANO}

\begin{tabular}{|l|l|l|l|l|l|l|}
\hline Año & \multicolumn{1}{|c|}{ Ciudad } & Países & Total atletas & Hombres & Mujeres & \% de mujeres en el total \\
\hline 1896 & Atenas & 13 & 241 & 241 & 0 & \\
\hline 1900 & París & 24 & 1225 & 1206 & 19 & 1.55 \\
\hline 1904 & St. Louis & 13 & 686 & 678 & 8 & 1.16 \\
\hline 1908 & Londres & 22 & 2035 & 1999 & 36 & 1.76 \\
\hline 1912 & Estocolmo & 28 & 2547 & 2490 & 57 & 2.23 \\
\hline 1920 & Antwerp & 29 & 2669 & 2591 & 78 & 2.92 \\
\hline 1924 & París & 44 & 3092 & 2956 & 136 & 4.39 \\
\hline 1928 & Ámsterdam & 46 & 3014 & 2724 & 290 & 9.62 \\
\hline 1932 & Los Ángeles & 37 & 1408 & 1281 & 127 & 9.01 \\
\hline 1936 & Berlín & 49 & 4066 & 3738 & 328 & 8.06 \\
\hline 1948 & Londres & 59 & 4099 & 3714 & 385 & 9.39 \\
\hline 1952 & Helsinki & 69 & 4925 & 4407 & 518 & 10.51 \\
\hline 1956 & Melbourne/ Estocolmo & 67 & 3184 & 2813 & 371 & 11.65 \\
\hline 1960 & Roma & 83 & 5348 & 4738 & 610 & 11.40 \\
\hline
\end{tabular}

Para un recuento muy completo de la ubicación histórica de las mujeres en el campo deportivo véase Hargreaves (1994).

3 Un ejemplo muy vivido de esta puesta en duda es el caso de Caster Semenya, velocista sudafricana que ha generado una polémica internacional. 


\begin{tabular}{|l|l|l|l|l|l|l|}
\hline 1964 & Tokio & 93 & 5140 & 4457 & 683 & 13.28 \\
\hline 1968 & México & 112 & 5530 & 4750 & 780 & 14.10 \\
\hline 1972 & Munich & 121 & 7123 & 6065 & 1058 & 14.85 \\
\hline 1976 & Montreal & 92 & 6028 & 4781 & 1247 & 20.68 \\
\hline 1980 & Moscú & 80 & 5217 & 4093 & 1123 & 21.52 \\
\hline 1984 & Los Ángeles & 140 & 6797 & 5230 & 1567 & 23.05 \\
\hline 1988 & Seúl & 159 & 8465 & 6279 & 2186 & 25.82 \\
\hline 1992 & Barcelona & 169 & 9367 & 6659 & 2708 & 28.91 \\
\hline 1996 & Atlanta & 197 & 10318 & 6806 & 3512 & 34.03 \\
\hline 2000 & Sydney & 199 & 10651 & 6582 & 4069 & 38.20 \\
\hline 2004 & Atenas & 201 & 10625 & 6296 & 4329 & 40.74 \\
\hline
\end{tabular}

Fuente: elaboración propia en base a Official Website of the Olympic Movement (s.f.).

Durante los últimos ciento cincuenta años, el campo deportivo se ha defendido de la intrusión femenina con diversas estrategias: desde la prohibición explícita vertida en los reglamentos y recogida en las legislaciones pertinentes, hasta la negligencia planificada de los organismos gubernamentales encargados de la promoción del deporte. Gracias a esta última, los presupuestos, los tiempos y los espacios se distribuyen por sistema de manera desigual entre hombres y mujeres ${ }^{4}$. Además, ha apelado al decoro (Hargreaves, 1994) para impedir que las mujeres muestren sus cuerpos semidesnudos y se exhiban en un espacio público, y se ha servido de racionalizaciones biologicistas - "las mujeres son más pequeñas, más lentas, más débiles que los hombres"- para justificar y mantener la segregación, cuando no la más franca y descarada discriminación.

Tengo razones para afirmar que el propio surgimiento del campo deportivo y su configuración como un sistema institucional moderno (siglos XIX y XX) implica y pone en funcionamiento una verdadera "política de género" cuya principal característica es la exclusión activa de las mujeres. Estos procesos se relacionan con las crónicas "crisis de la masculinidad" (Kimmel, 1987) que han acompañado el siglo de mayor desarrollo del estatus y los derechos de las mujeres y que, en el ámbito de la "construcción del cuerpo humano", encuentran una resolución factible con la creación de una "arena social" específicamente masculina. Un coto celosamente guardado donde se negocia y se reestablece la definición del género, sus límites y sus rasgos distintivos.

Sin embargo, lo que me interesa ensayar en este texto es una respuesta contraintuitiva y no tautológica a la pregunta que le da inicio. Para lograr este objetivo me sirvo

Para una documentada discusión de las objeciones legales en Estados Unidos a la participación de mujeres en el deporte, en el contexto de la reforma para la igualdad de derechos (ERA, por sus siglas en inglés), véase Fields (2005). 
de la noción de tecnologías de género. La he tomado de Teresa de Lauretis (1987; 2000), aunque en mi ulterior desarrollo quizá la haya subvertido y desvirtuado sin remedio.

\section{II. “EL ÚLTIMO ES VIEJA”}

En México, la ineptitud de las mujeres para las actividades físicas y para cualquier clase de juego donde haga falta alguna destreza corporal, se mitifica en el desprecio con que los varones se refieren a las hembras de la especie al Ilamarlas "las viejas". El enigma lingüístico de porqué se les dice "viejas" incluso a las niñas no es cuestionable, como tampoco la certeza de que ser "vieja" implica estar en desventaja física. La frase "iel último es vieja!" es la señal de arranque de cualquier carrera para una parvada de criaturas de uno y otro sexo. El estigma de perder implica la puesta en duda de la hombría. Pero ¿qué pasa cuando la que gana es una "vieja"?

En "Throwing like a girl"5, Iris Marion Young (1990) denuncia la naturalización de la ineptitud femenina en el campo deportivo. Este multicitado ensayo esboza de manera provisional "algunas modalidades básicas del comportamiento del cuerpo femenino, su manera de moverse y su relación con el espacio"6. Lo que la autora pretende es aportar inteligibilidad y significación a ciertas maneras"observables y más bien ordinarias en que, en nuestra sociedad, las mujeres, típicamente, se comportan y se mueven de forma diferente que los hombres" (Ibíd: 143).

Según Young, la orientación deliberada del cuerpo hacia las cosas y hacia el espacio define la relación del sujeto con el mundo. Por lo tanto, la manera en que el cuerpo femenino se conduce en ese terreno puede ser particularmente reveladora de las estructuras de la existencia femenina. Por ejemplo, a menudo, el movimiento efectuado por una mujer corta y separa la relación mutuamente condicionada entre intención y acto. "La existencia corporal femenina es una intencionalidad inhibida que simultáneamente se dirige hacia un fin proyectado con un 'puedo' y retira su total compromiso corpóreo a tal fin en un auto-impuesto 'no puedo"' (Ibíd: 148-150). Este carácter produce una unidad discontinua entre la existencia corpórea femenina y sus alrededores, pero también una falta de unidad corporal.

La relación de las mujeres con el espacio es particularmente reveladora, porque ahí su existencia es precaria. Hay una atribución de propiedad del espacio que pone a las mujeres, con enorme frecuencia, en un "fuera de lugar", en un lugar marginal, de exclusión, de otredad. El propio estilo de ocupación del espacio está atravesado por el género desde el momento en que el "estar en el espacio" de las mujeres es diferente

"Lanzar (una pelota) como niña".

Todas las traducciones son nuestras. 
del de los hombres. La diferencia tiene que ver con la amenaza de invasión al propio cuerpo:

"La forma más extrema de tal invasión espacial y corporal es la amenaza de violación. Pero diariamente [una mujer] está sometida a la posibilidad de invasión corporal de modos mucho más sutiles (...). Yo sugeriría que el espacio encerrado que ha sido descrito como un tipo de espacialidad femenina es en parte una defensa contra tal invasión. Las mujeres tienden a proyectar una barrera existencial a su alrededory que las desconecta de lo 'externo' para mantener al otro a distancia. La mujer vive su espacio como confinado y cerrado en torno suyo, por lo menos en parte para proyectar alguna pequeña área en donde puede existir como sujeto libre" (Ibíd: 155).

Entre las raíces que pueden explicar las modalidades contradictorias de tal existencia corpórea está el hecho de que el cuerpo de las mujeres con frecuencia se vive a la vez como sujeto y como objeto. Una mujer se considera el objeto del movimiento, en lugar de su origen; no se siente segura de sus capacidades corporales ni cree tener control sobre sus movimientos. Debe dividir su atención entre la tarea que realiza y el cuerpo, que debe ser coaccionado y manipulado para llevarla a cabo. Además, la existencia corpórea femenina es auto-referencial hasta el punto en que dispone su movimiento como algo que es observado, como el objeto de la mirada de otro: "el cuerpo se vive a menudo como una cosa que es otra que sí mismo, una cosa como otras cosas en el mundo" (Ibíd: 150). Una mujer cuida "las apariencias" mucho más que un hombre: no quiere verse desgarbada ni demasiado fuerte. Por eso, se mira al espejo, se preocupa de cómo se ve. Por eso reduce, le da forma, moldea y decora su cuerpo.

Muchas mujeres viven el espacio disponible para el movimiento como algo constreñido: con frecuencia "respondemos al movimiento de una pelota que viene hacia nosotras como si viniera contra nosotras, y nuestro impulso corporal inmediato es quitarnos, agacharnos o protegernos de alguna manera" (Ibíd: 146). Esto indica una carencia de confianza en el propio cuerpo: en apariencia, el miedo a salir lastimadas es mayor en las mujeres que en los varones. A menudo "experimentamos nuestros cuerpos como un estorbo frágil, en lugar de verlos como el medio para la puesta en acto de nuestras intenciones" (Ibíd: 146-147).

En última instancia, para Young, las modalidades del comportamiento, la movilidad y la espacialidad del cuerpo femenino exhiben una tensión entre trascendencia e inmanencia, entre subjetividad y objetualización (Ibíd: 144). Pero para llegar a este desenlace abstracto, la autora se sirve de descripciones puntuales de las diferencias entre cuerpos femeninos y cuerpos masculinos. Su referente filosófico principal es la fenomenología de la percepción de Maurice Merleau-Ponty. Este enfoque le permite entender el significado fundamentalmente genérico de posicionamientos corporales tipificados: 
"No sólo hay un estilo típico para lanzar como niña, sino que hay un estilo más o menos típico de correr como niña, trepar como niña, columpiarse como niña, golpear como niña. Lo que tienen en común, primero, es que no se pone todo el cuerpo en un movimiento fluido y dirigido, sino que más bien, al balancearse o al golpear, por ejemplo, el movimiento se concentra en una parte del cuerpo; y segundo, que el movimiento de la mujer tiende a no alargar, extender, inclinar, encoger o seguir hasta el final la dirección de su propósito" (Ibíd: 146).

La confirmación de la diferencia -el hecho innegable de que existe un "estilo general femenino de comportamiento y motilidad" (Ibíd: 147)- le permite a la autora reflexionar en torno a la construcción de la diferencia en los estilos corporales y concluir que no hay “una conexión misteriosa, inherente, entre estas modalidades de comportamiento típico y el hecho de ser una persona del sexo femenino"7. En esta línea, encuentra dos propensiones concomitantes, aunque ambas azarosas y contingentes (dado que ninguna de las observaciones se aplica a todas las mujeres todo el tiempo). Por un lado, muchas modalidades son el resultado de la falta de práctica en el uso del cuerpo y en el cumplimiento de tareas; a las mujeres y las niñas no se les estimula tanto como a los varones para desarrollar habilidades corporales específicas. Además, el juego de las niñas "a menudo es más sedentario y encerrado que el juego de los niños" (Ibíd: 154).

Pero, por otro lado, las "modalidades de la existencia corpórea femenina" no son meramente negativas; su fuente no está sólo en la falta de práctica, sino también en una constitución activa y dirigida del cuerpo y del estilo corporal que comienza a aprenderse desde el momento en que una niña "empieza a entender que es una niña" (Ibíd.):

"La niñita adquiere muchos hábitos sutiles de comportamiento corporal femenino (...), aprende activamente a entorpecer sus movimientos. Se le dice que debe ser cuidadosa para no lastimarse, no ensuciarse, no desgarrar su ropa; se le dice que las cosas que desea hacer son peligrosas para ella (...). Cuanto más asume una niña su estatus como femenino, más se toma a sí misma como alguien frágil e inmóvil, y pone en acto más activamente su propia inhibición corporal" (Ibíd.).

\section{EL ÁMBITO CONCEPTUAL DE LA NOCIÓN DE TÉCNICA Y TECNOLOGÍA}

Teresa de Lauretis desarrolla la noción de "tecnologías de género" en un texto donde nos introduce en uno de sus temas principales de análisis: el problema de la representación. El campo de aplicación del concepto es la crítica cinematográfica y el principal ejemplo de la autora para una "tecnología social"es el cine como vehículo en

Para una visión comprehensiva de cómo la fenomenología y sus derivaciones han influido en el análisis feminista del cuerpo véase Grosz (1994); Spelman (1982); Bordo (1993); Cole (1993); Fausto-Sterling (2000); Baz (1996); Buñuel Heras (1995); Butler (2001, 2002, 2006) y Esteban (2004). Entre los autores que permiten entender el cuerpo como una construcción social véase Laqueur (1994); Turner (1989); Vigarello (2005a, 2005b, 2005c); Bernard (1994) y Crossley $(1996,2001,2004)$. 
la producción de representaciones de género. Para explicar el concepto de "tecnología", su referente teórico es Foucault -específicamente su Historia de la sexualidad-, de quien toma la idea de que las prohibiciones y las reglas producen relaciones sociales (de Lauretis, 2000: 47).

La idea de "tecnología" que Foucault desarrolla cuando estudia la"sociedad disciplinaria" tiene que ver con la formación histórica de procedimientos mediante los cuales se constituye el "sujeto-sujetado". Es decir, con el desarrollo de "técnicas de poder orientadas a los individuos e interesadas en dirigirlos en una dirección continua y permanente" (Morey; citado en Foucault, 1990: 42)8. En una primera aproximación, Foucault distingue cuatro tipos diferentes, aunque señala que "casi nunca funcionan de modo separado": i) tecnologías de producción, ii) tecnologías de sistemas de signos, iii) tecnologías de poder y iv) tecnologías del yo. Estas últimas

"permiten a los individuos efectuar, por cuenta propia o con la ayuda de otros, cierto número de operaciones sobre su cuerpo y su alma, pensamientos, conducta o cualquier forma de ser, obteniendo así una transformación de símismos con el fin de alcanzar cierto estado de felicidad, pureza, sabiduría o inmortalidad" (Foucault, 1990: 48).

Pero este tipo de procedimientos también puede orientarse en otra dirección, ligada hacia la "suje[ta]ción del sujeto". Por eso Foucault habla, un poco más adelante, de las "tecnologías de dominación" (Ibíd:49). Como parte de su proyecto genealógico, lleva a cabo el recuento histórico y la descripción de una serie de técnicas y procedimientos del poder cuyo objetivo es incidir en la formación de cierto tipo de sujetos ${ }^{9}$. Comienza con prácticas griegas, técnicas estoicas (la meditación, la gymnasia, la interpretación de los sueños) y continúa con técnicas del cristianismo primitivo (la exomologesis o "reconocimiento del hecho"y la exagouresis o "sacrificio de sí, del deseo propio del sujeto", mediante la cual no hay "ni un solo momento en el que el monje pueda ser autónomo" (Ibíd: $82,86,87-88)^{10}$. Uno de los puntos de interés de este recorrido es que ilustra diversas formas en que este tipo de trabajo individual (las tecnologías del yo) sobre la propia vida (el cuerpo y el alma) puede dar como resultado un sometimiento voluntario al

$8 \quad$ El juego de palabras "sujeto-sujetado" se origina en la homonimia de la palabra sujet, que en francés significa al mismo tiempo sujeto y súbdito. En español, la idea de "sujeto-sujetado" trataría de aludir al proceso de constitución de la subjetividad como "la individualización y la totalización simultáneas de las estructuras del poder moderno" (Morey; citado en Foucault, 1990: 24).

$9 \quad$ Sobre las genealogías como "anticiencias", véase Foucault (2002: 21-23).

10 Según Vázquez y Moreno, la penitencia de la exomologesis "tenía lugar una sola vez en la vida (...); implicaba una transformación completa del sujeto, convertido en penitente para el resto de sus días" (Vázquez y Moreno, 1997: 53), mientras que la exagouresis "es un procedimiento limitado al ámbito de la vida monástica, cuya forma de veridicción consiste en una hermenéutica de sí, una vigilia y desciframiento de los propios pensamientos. Éstos deben ser expuestos constante y exhaustivamente al director espiritual, que interpretará su sentido discriminando las ideas engañosas infundidas por el Maligno (...) y los pensamientos puros y buenos que tienen su origen en Dios (...); implica algo nuevo: una relación perpetua de obediencia y renuncia absolutas" (Ibíd: 59-60). 
poder donde, por ejemplo, la obediencia "debe abarcar todos los aspectos de la vida monástica"11. Finalmente, el autor detecta el origen de ese poder individualizador, centralizado y centralizador que bautizará como "pastorado"12, el cual se sustenta en técnicas "orientadas hacia los individuos y destinadas a gobernarlos de manera continua y permanente" (Ibíd: 98).

La reflexión foucaultiana encuentra una perspicaz interlocución en la crítica de Michel de Certeau. Las ideas de este autor me resultan de particular utilidad pues permiten introducir como un tema relevante el hacer de aquellos sujetos que se mueven en y tratan de apropiarse de un espacio ajeno.

En La invención de lo cotidiano, De Certeau (1996) busca una contrapartida para la "cuadrícula de la vigilancia" y se pregunta - "del lado de consumidores (¿o dominados?)" - por aquellos procedimientos y ardides que juegan con los mecanismos de la disciplina (mecanismos a partir de los cuales se organiza el orden sociopolítico) para cambiarlos y componer un "ambiente de antidisciplina"13. Lo que se propone es "devolver su legitimidad lógica y cultural a las prácticas cotidianas" (Ibíd: XLIV-XLVII).

Para De Certeau es imposible "reducir los funcionamientos de una sociedad a un tipo dominante de procedimientos" o dispositivos tecnológicos (por ejemplo, los procedimientos panópticos que estudia Foucault) cuyo papel histórico ha consistido

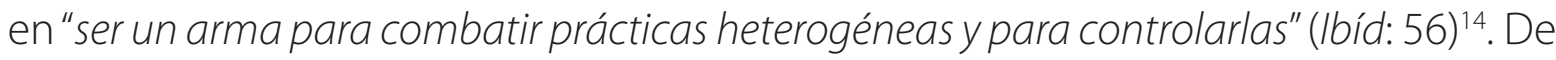
esta forma, bajo el "monoteísmo al cual se podría comparar el privilegio que los dispositivos panópticos se han asegurado, sobreviviría un 'politeísmo' de prácticas diseminadas" (Ibíd: 57); prácticas innumerables

"(...) que siguen siendo 'menores', siempre presentes ahí aunque no organizadoras de discurso, y aptas para conservar las primicias o los restos de hipótesis (institucionales, científicas) diferentes para esta sociedad o para otras. Y es en esta múltiple y silenciosa 'reserva' de procedimientos donde las prácticas 'consumidoras' tratarían, con la

11 "Desde el siglo xVIII hasta el presente, las técnicas de verbalización han sido reinsertadas en un contexto diferente por las Ilamadas ciencias humanas para ser utilizadas sin que haya renuncia al yo, pero para constituir positivamente un nuevo yo. Utilizar estas técnicas sin renunciar a sí mismo supone un cambio decisivo" (Foucault, 1990: 94).

12 "De todas las sociedades de la historia, las nuestras (...) fueron las únicas en desarrollar una extraña tecnología de poder cuyo objeto era la inmensa mayoría de los hombres agrupados en un rebaño con un puñado de pastores" (Foucault, 1990: 103-104).

13 "Estas 'maneras de hacer' constituyen las mil prácticas a través de las cuales los usuarios se reapropian del espacio organizado por los técnicos de la producción sociocultural (...): formas subrepticias que adquiere la creatividad dispersa, táctica y artesanal de grupos o individuos atrapados en lo sucesivo dentro de las redes de la 'vigilancia"' (De Certeau, 1996: xliv-xlv).

14 No obstante esas reservas, De Certeau reconoce que Foucault, al mostrar la heterogeneidad y las relaciones equívocas de los dispositivos y de las ideologías, "ha constituido en objeto histórico tratable esta zona donde los procedimientos tecnológicos tienen efectos de poder específicos, obedecen a funcionamientos lógicos propios y pueden producir un desvío fundamental en las instituciones del orden y del conocimiento" (De Certeau, 1996: 57). 
doble característica, señalada por Foucault, con modos a veces minúsculos, a veces mayoritarios, de poder organizar a la vez espacios y lenguajes" (Ibíd: 56).

\section{MASCULINO/FEMENINO: HACER GÉNERO}

Lo que Teresa de Lauretis quiere explorar en el "medio cinemático" es la forma en que se producen las concepciones culturales de lo masculino y lo femenino. Para De Lauretis, se trataría de categorías complementarias y mutuamente excluyentes dentro de las que están colocados todos los seres humanos dependientes del "sistema de género" (descrito como un "sistema de sentido") dentro de cada cultura. Según la autora, en los procesos simbólicos, el mecanismo de la representación tendría la propiedad de asociar el sexo a contenidos culturales dentro de una escala de valores y jerarquías sociales. La relevancia de la representación residiría en el hecho de que "la traducción cultural del sexo en género está sistemáticamente unida a la organización de la desigualdad social" (De Lauretis, 2000: 38).

A pesar del desliz - muy ligado con su tiempo- en que opone la categoría de género a la de sexo en una especie de juego de equivalencias entre sexo=biología / género=cultura, la noción de "tecnología de género" tiene una indudable cualidad dinámica. Al perfilarla, De Lauretis define el género como un "complejo de costumbres, asociaciones, percepciones y disposiciones que nos generan como mujeres" (Ibíd: 54) y asegura que "la construcción del género es al mismo tiempo el producto y el proceso de su representación" (Ibíd: 39). Las tecnologías de género, por tanto, estarían ligadas con prácticas socioculturales, discursos e instituciones capaces de crear "efectos de significado" en la producción de sujetos hombres y sujetos mujeres. En conclusión, el género y las diferencias sexuales serían efecto de representaciones y prácticas discursivas.

En este trabajo, recupero de Teresa de Lauretis su concepción del género como un proceso, en lugar de un hecho terminado; como un complejo conjunto de fenómenos sociales capaz de producir hombres y mujeres. Con lo que pretendo ampliar su planteamiento inicial es con la presunción de que las tecnologías de género actúan no sólo en el plano simbólico, sino también, y sobre todo, de forma física, en la propia producción del cuerpo e inclusive en la producción del sexo. Lo que me interesa es explorar los procesos de incorporación (en el sentido de embodiment) de las disposiciones a partir de las cuales se configura la propia materialidad de los cuerpos ${ }^{15}$.

El ámbito donde quiero aplicar esta idea es la arena deportiva. Quiero caracterizar los deportes como tecnologías de género, es decir, como procedimientos sociales

Lo cual no significa negar que exista un sustrato biológico como base de la existencia humana. No obstante, existe una discusión importante respecto de la manera en que se construyen nuestras percepciones sobre el sexo. Al respecto, véase Kessler y McKenna (1978); Lorber (1993); Spelman (1982); Grosz (1994); Butler (2002); Fenstermaker y West (2002); Laqueur (1994) y, sobre todo, los trabajos de Anne Fausto-Sterling. 
cuya finalidad es la de producir el género, la de "hacer género". Se trata de regímenes complejos, donde deben incluirse, sin duda, las prácticas discursivas, los proyectos pedagógicos, las normatividades y la implantación de representaciones. Pero también, de manera central, las actividades, maniobras y operaciones a partir de las cuales esos proyectos, normas e imágenes se corporifican, se vuelven carne. Este renglón abarcaría desde los hábitos alimenticios y los sistemas de entrenamiento hasta el uso de drogas (prohibidas o no) y la aplicación de métodos quirúrgicos, pasando por la configuración del espacio y las prácticas de segregación.

¿En qué sentido puede hablarse de los deportes como tecnologías de género? Por lo menos en tres: i) porque relegan y discriminan a las mujeres al crear un campo (una arena social) estrechamente vigilado de exclusividad masculina, donde se prohíbe explícitamente la participación de aquéllas; cuando esa prohibición está en peligro de verse vulnerada, entra en funcionamiento una serie de mecanismos de exclusión, entre los que se puede contar desde la construcción de espacios hipermasculinizados hasta el desprestigio público de las atletas, pasando por la separación y la especialización de las actividades deportivas con estrategias tales como las variantes reglamentarias o la prueba de sexo; ii) porque codifican y prescriben, institucionalmente y a gran escala, actividades y estilos diferenciados entre hombres y mujeres con prácticas corporales individuales o colectivas cuyo objetivo explícito es el de fomentar la masculinidad ${ }^{16}$; y iii) porque, junto con las prácticas corporales, producen representaciones sociales del género que afectan las disposiciones, percepciones y acciones de las personas individuales respecto de sus cuerpos en una organización jerárquica, donde se prescribe la fuerza como cualidad masculina y la fragilidad como cualidad femenina.

Mi pretensión es problemática, dado que los procesos de producción del género tienen como principal propiedad la de ocultar su carácter de proceso y de creación. Cuando hablo de tecnologías de género me refiero a la capacidad del habitus para engendrar conductas "razonables" (consensuales, homogéneas, inteligibles, previsibles y autoevidentes) que tienen un refuerzo continuo; prácticas "objetivamente ajustadas a la lógica característica de un determinado campo del que anticipan el porvenir objetivo" (Bourdieu, 1991: 97) ${ }^{17}$.

Para el sentido común, el campo deportivo se presenta como un ámbito de exhibición de "la naturaleza corporal del hombre", además de que se pretende neutral respecto al sexo. No obstante, se trata de uno de los espacios sociales más artificializados y más

16 Como afirma Connell: "los diferentes regímenes de ejercicio para hombres y mujeres, las prácticas disciplinarias que se enseñan y que constituyen el deporte, se diseñan para producir cuerpos ligados al género. Si la disciplina social no puede producir cuerpos que se adecuen a la noción de género específica, entonces el bisturí sí podrá hacerlo" (Connell, 2003: 79).

17 Recupero la reflexión de Bourdieu sobre el habitus como sistema de disposiciones estructuradas y estructurantes constituido en la práctica y orientado hacia funciones prácticas; como principio generador y organizador de prácticas y representaciones (Bourdieu, 1991: 48, 94). 
intensa y activamente generificados. Parafraseando a Bourdieu (2000), diría que las tecnologías de género (los deportes en particular) transforman la historia en naturaleza y la arbitrariedad cultural en necesidad natural. En la tarea de "hacer el género" ocultan el carácter arbitrario y contingente de la diferencia entre lo masculino y lo femenino.

Es este doble movimiento, el de crear y ocultar, lo que De Lauretis enfatiza cuando escribe la palabra "tecno-logías", con un guion que une y separa los dos aspectos del proceso: por un lado, la técnica como procedimiento de aprendizaje o mecanismo de adiestramiento, y, por el otro, el logos como saber, como un "juego de verdad" (Foucault, 1990) relacionado con una técnica específica. La razón de este oscurecimiento del proceso debemos buscarla en un elemento que Foucault explora en varios puntos de su obra: la micromecánica, la trama efectiva de las relaciones de poder (Foucault, 2002: 41, 51). De esta forma, el estudio del campo deportivo se integra al proyecto foucaultiano de estudiar el poder como proceso de constitución progresiva y material de "los súbditos [sujets], el sujeto [sujet], a partir de la multiplicidad de los cuerpos, las fuerzas, las energías, las materias, los deseos, los pensamientos, etcétera" (Ibíd: 37).

El conjunto heterogéneo de posturas teóricas hasta aquí presentado tiene en común la posibilidad de entender los deportes como algo más que la mera experiencia corporal individualizada, para convertirse en sistemas (artes, mecanismos, aparatos, operadores, instrumentos o dispositivos) portadores de significación en diferentes registros, desde la construcción del cuerpo atlético hasta su mercantilización en el espectáculo mass-mediático. El uso de la categoría desemboca, de manera central, en los procesos de "masculinización"y "feminización".

Defino entonces las "tecnologías de género" como procedimientos históricos, sociales, culturales e intencionales. La idea de procedimiento me remite al ámbito de la representación, pero también al ámbito de la acción: se trata de un campo del "hacer" cuya finalidad es la producción de sujetos diferenciados a partir de la atribución de pertenencia a una de dos clases (hombre/mujer) con características y cualidades definidas en función de una supuesta complementariedad mutua. En la práctica deportiva, esta "producción" no se limita a la subjetividad (pensada como interioridad), sino que se extiende sobre todo a la corporalidad, a esa dimensión material y objetiva de la existencia humana que en ciertos discursos teóricos se considera "natural". La idea de "tecnologías de género" pretende deconstruir tal "naturalidad" al identificar los procesos en que el propio cuerpo es creado en sintonía con su subjetividad.

En otro contexto, la perspectiva etnometodológica en los estudios de género, propuesta en West y Zimmerman (1987) y Fenstermaker y West (2002), nos permite explorar el campo deportivo como un ámbito donde"se hace el género"18. Esta reflexión

"Los estudios etnometodológicos analizan las actividades cotidianas como métodos que sus miembros usan para 
es muy afín con la de Austin — retomada por Butler - sobre los actos performativos como ceremonias, rituales y fórmulas sociales cuya principal (si no es que única) finalidad es la de producir aquello que están nombrando. Ambas propuestas conceptuales permiten examinar la forma de funcionamiento de instituciones, discursos y dispositivos sociales cuyo objetivo es crear, subrayar y codificar las diferencias que permiten distinguir con nitidez, en todo momento y lugar, a los hombres de las mujeres, a las mujeres de los hombres.

Butler (2001) aplica este planteamiento al postular las relaciones sociales como los espacios donde se fabrica, mediante actos performativos, aquello que consideramos la "esencia interna del género" (15-16). Una de las principales aportaciones de esta autora consiste en ampliar la comprensión de la performatividad más allá del hecho lingüístico, como un procedimiento teatral donde se escenifica la identidad y "el discurso mismo es un acto corporal con consecuencias lingüísticas específicas" (24).

Resulta de particular importancia la reflexión butleriana de la "identidad" como un ideal normativo, y no sólo como un rasgo descriptivo de la experiencia. Para Butler, la "coherencia" y la "continuidad" no son "rasgos lógicos o analíticos de la calidad de persona sino, más bien, normas de inteligibilidad socialmente instituidas y mantenidas" (Ibíd: 49-50) a partir de las cuales se puede reducir la ontología del género a un juego de apariencias: "la mascarada puede entenderse como la producción performativa de una ontología sexual, un parecer que se hace convincente como si fuese un 'ser'" (Ibíd: 81).

En la medida en que aceptamos que la identidad tiene una dimensión performativa, podemos analizarla "como un logro rutinario, metódico y recurrente"19. Este logro depende de la competencia de hombres y mujeres para llevar a cabo un conjunto abigarrado de actividades cuyo propósito es expresar la "naturaleza" de la identidad, su índole "esencial y profunda" (West y Zimmerman, 1987: 126).

La consideración del género como discurso encarnado, como significación que se materializa en el cuerpo, es de particular relevancia para mi propio razonamiento. Desde este punto de vista, el cuerpo no es ya un objeto natural y estático ni un recipiente pasivo de estímulos del exterior, sino un agente que se realiza en su propia

hacer que esas actividades sean racionalmente-visibles-y-reportables-para-todos-los-efectos-prácticos; [se trata de] descubrir las propiedades formales de las acciones prácticas ordinarias y de sentido común, desde 'dentro' del escenario concreto, como continuas realizaciones de esos mismos escenarios" (Garfinkel, 2006: 1-2).

19 Con "dimensión performativa" me refiero a la actuación de que la identidad es objeto, y de la cual existe una amplia conciencia: para ser quienes somos, nos interpretamos a nosotros mismos en escenarios sociales frente a públicos que aceptan nuestra actuación (Goffman, 1959). Utilizo la noción de performance en el sentido de que la representación es nuestra única vía de acceso al ser, porque ser quienes somos es para cada quien obligatorio e inevitable. La traducción al español de este término cubre buena parte del campo semántico al que me quiero referir: perform = llevar a cabo, realizar, cumplir, desempeñar, interpretar, funcionar; performance = interpretación, actuación, función, sesión, funcionamiento, rendimiento; performer = intérprete, actor/actriz. 
actuación de manera deliberada y consecuente, aunque esta realización implique un posicionamiento [placement] que no está sujeto a elección, pues depende de la adscripción binaria mujer/hombre a la que los seres humanos somos sometidos desde el nacimiento (y en la época actual, incluso desde antes) en función de la lectura que nuestros progenitores hacen de la configuración de nuestros genitales ${ }^{20}$.

\title{
Figura 1 CAUSALIDAD DE IDA Y DE VUELTA A TRAVÉS DE DIVERSOS NIVELES DE ANÁLISIS
}

\author{
Entorno físico y ecológico \\ 1 \\ Relaciones sociales \\ $\uparrow$ \\ Conducta/experiencia individual \\ $\downarrow$ \\ Anatomía y fisiología (estructuras y procesos corporales) \\ $\uparrow$ \\ Bioquímica (proteínas y otras moléculas) \\ $\uparrow$ \\ ADN (planos de diseño para las proteínas)
}

Fuente: Goldstein (2002: 120).

En el abordaje del campo deportivo, nos interesa particularmente el poder que tiene el discurso para crear instituciones que activan prácticas específicas cuyo principal influjo se concentra en la corporalidad, en la producción de cierto tipo de cuerpos mediante procesos afines a los que Foucault ha denominado "tecnologías del yo". Como actos performativos de género (es decir, como acciones que constituyen subjetividad), tales procesos no sólo crean identidades de género (no sólo nos proveen de elementos significativos para la diferenciación entre clases-sexuales), sino que también organizan las condiciones ecológicas ( $v$. gr., en instalaciones como campos deportivos, gimnasios, escuelas), sociales (v.gr., al poner en marcha mecanismos de exclusión), conductuales (v. gr., con el diseño de planes de entrenamiento), fisiológicas (dado que prácticas y condiciones influyen en el funcionamiento del organismo) e incluso bioquímicas (en la medida en que prescriben programas alimentarios y hasta el uso de ciertas drogas, como analgésicos, desinflamantes o esteroides anabólicos) a partir de las cuales se organiza un determinado proyecto institucional para producir, y al tiempo ocultar su

"En todas las sociedades, todas las criaturas al nacer son ubicadas en una de las dos clases-sexuales (...) Este posicionamiento derivado de la configuración física permite una etiqueta de identificación vinculada al sexo" (Goffman, 1977: 302). "El posicionamiento de clase-sexual es casi sin excepción exhaustivo en la población y dura toda la vida (...); en la sociedad moderna sentimos que macho-hembra es una división social que funciona en completa y real armonía con nuestra 'herencia biológica'; [en contraste], el término 'clase-sexual' significa el uso de una categoría que es puramente sociológica, la cual funciona solamente en esa disciplina y no en las ciencias biológicas" (Ibíd: 302-303). 
carácter construido, cierto tipo de configuraciones corporales correspondientes con esas identidades ${ }^{21}$.

La institución deportiva pone a la disposición de los sujetos "conjuntos discretos y bien definidos de conductas" (West y Zimmerman, 1987: 135), los cuales pueden ser usados para producir actuaciones reconocibles de masculinidad, pero estas actuaciones nunca se quedan en el plano de la escenificación como puro juego de signos, sino que inciden en la materialidad del cuerpo. Tales orientaciones no tienen un carácter rígido, por el contrario, se adaptan a las diferentes interacciones sociales en que se ve sumergido un individuo. "Hacer género" consiste en manejar cualquier ocasión de modo que, sin importar las particularidades del caso, el resultado se vea en contexto y sea apropiado, aunque no significa "cumplir invariablemente con las concepciones normativas", sino comprometerse con ciertas conductas y correr el riesgo de que éstas sean evaluadas en función de esa normatividad (Ibíd: 136-137).

El esfuerzo cultural de "hacer género" consiste en crear diferencias entre niñas y niños, entre mujeres y hombres, diferencias que moldean cuerpos y mentes, y que se usan para poner en escena aquello que se considera como "natural" o "normal". En consecuencia, convierte los arreglos basados en la categoría de sexo en maneras legítimas de organizar la vida: el orden social aparece como una mera acomodación al orden natural. "Las diferencias entre mujeres y hombres que son creadas por este proceso pueden entonces ser retratadas como disposiciones fundamentales y duraderas" (Ibíd: 146), es decir, como habitus 22 .

En el análisis de Goffman (1977) -una de las fuentes conceptuales de West y Zimmerman-, los deportes y los juegos competitivos constituyen un escenario "donde los varones jóvenes pueden gastar sus energías animales"(322), hacer ejercicio, medirse contra la adversidad y, además, entrenarse en el uso de herramientas útiles (lealtad, rectitud, perseverancia y espíritu de equipo) para "el juego de la vida" (Ibíd.). Se trata de un ámbito artificial que se ofrece como marco para la adquisición de las características codificadas de una identidad específicamente masculina. Como institución social, el campo deportivo es un universo cerrado en sí mismo; todas las otras funciones que cumple -por ejemplo, de espectáculo o entretenimiento- aparecen como subsidiarias de su designio primordial. Este designio es el de dar existencia en la práctica a la única expresión que el

21 "El efecto sustantivo del género se produce performativamente y es impuesto por las prácticas reglamentadoras de la coherencia de género (...); el género siempre es un hacer, aunque no un hacer por parte de un sujeto que se pueda considerar preexistente a la acción (...): no hay una identidad de género detrás de las expresiones de género; esa identidad se constituye performativamente por las mismas 'expresiones' que, según se dice, son resultado de ésta" (Butler, 2001: 58).

22 Para Bourdieu (1996), las identidades distintivas que instituye el nomos cultural se encarnan -bajo la forma de habitus claramente diferenciados- como "categorías de percepción susceptibles de ser aplicadas a cualquier cosa, comenzando por el cuerpo, bajo la forma de disposiciones socialmente sexuadas" (34) y como "una somatización de las relaciones sociales de dominio a través de un formidable trabajo colectivo de socialización difusa y continua" (lbíd.). 
mundo moderno admite de la"naturaleza masculina"; el de constituirse como un sistema de referencia que aporta pruebas para demostrar que tal naturaleza existe ${ }^{23}$.

\begin{abstract}
"Los deportes son la única expresión de la naturaleza humana masculina: un arreglo específicamente diseñado para permitir a los varones manifestar las cualidades que se declaran como básicas para ellos: fuerza de varios tipos, energía, resistencia, etcétera" (Ibíd.).
\end{abstract}

A estas manifestaciones de atributos generificados —o despliegues de génerolas denomina el autor "generismos" [genderisms]. Se trata de escenarios y recursos expresivos que permiten la puesta en acto del género: "los hombres y las mujeres son capaces de examinar cualquier actividad social para encontrar medios a través de los cuales expresar el género" (Ibíd: 325). Como tales, "no es que permitan la manifestación de diferencias naturales entre los sexos, sino que proveen la producción de esa diferencia en sí misma" (Ibíd: 324), pues se usan para la exhibición y consolidación de la identidad de género. En virtud de que el género es un indicador de diferenciación relevante en prácticamente todas las relaciones humanas, la producción y el empleo de generismos resulta una de las principales prácticas significativas en la interacción social ${ }^{24}$.

Goffman nos recuerda que la producción de esa diferencia no es sólo un hecho de significación. Es decir, no sólo se debe interpretar como un asunto subjetivo, inmaterial, simbólico, sino también (sobre todo en el campo deportivo) es un hecho corporal en tanto las normas de la masculinidad dan como resultado diferencias objetivas (fuerza, musculatura, poder, rudeza, resistencia, velocidad) entre las clases-sexuales. Esas mismas propiedades materiales de los cuerpos, aunque no sean "naturales" sino configuradas en un entorno diseñado con el propósito de producirlas, se convierten en generismos. De esta forma:

"ciertas prácticas institucionales profundamente arraigadas tienen el efecto de transformar las situaciones sociales en escenas para el performance de generismos de ambos sexos, y muchos de estos performances toman una configuración ritual que afirma nuestras creencias sobre la naturaleza humana diferencial de los sexos" (Ibíd: 325).

23 Según Goffman (1977), en los círculos sociales comunes las ocasiones para el uso de la coerción física son muy raras. En la medida en que ese uso es un indicador social de masculinidad, podemos decir que el entorno social es poco cooperativo en la exhibición del género (322-323).

24 "Cada alrededor, cada habitación, cada espacio para las reuniones sociales, necesariamente provee materiales que pueden ser usados en el despliegue y la afirmación de la identidad de género (. . .); la organización del habla pondrá a la disposición de los participantes una gran cantidad de situaciones que pueden ser usadas como signos (...). Es aquí donde la clase-sexual se hace sentir, en la organización de la interacción cara a cara, pues aquí los entendimientos sobre el dominio basado en el sexo pueden ser empleados como medio para decidir quién decide, quien guía y quién es guiada" (Goffman, 1977: 324). 


\section{PODER EN EL CUERPO, CUERPO EN EL PODER}

"El deporte ha sido y sigue siendo un mecanismo ideológico particularmente poderoso porque está dominado por el cuerpo, un lugar de condensación ideológica cuyo sentido manifiesto está íntimamente ligado a lo biológico. Los saberes biológicos (los efectos de verdad foucaultianos) y su atractivo hacia lo natural (las narrativas del cuerpo) trabajan para disolver los rastros de la cultura, del trabajo productivo y del entrenamiento sobre el cuerpo y sus movimientos" (Cole, 1993: 86).

Entre las interpretaciones feministas más agudas de las diferencias físicas entre hombres y mujeres hay una sospecha recalcitrante: las mujeres no son débiles por naturaleza, sino que hay una enorme cantidad de fuerzas sociales (organizadas como tecnologías de género) encargadas de debilitarlas. Entre ellas, el discurso impecable que las constituye como humanidad deficitaria. Desde mi punto de vista, el valor de este debate no tiene tanto que ver con la postulación de una naturaleza de varones y otra de mujeres en términos de la existencia o no de una diferencia esencial, sino con los efectos que este postulado impone en la vida de las mujeres.

Obviamente, las corporalidades de hombres y mujeres son diferentes; pero si el cuerpo comienza a ser pensado como algo más que un organismo biológico con un destino inalterable inscrito en el código genético -en particular, si los aspectos biológicos no se consideran como hechos cerrados y unidireccionales-, su comprensión requiere un movimiento a lo largo de diversos niveles de análisis.

El cuerpo no es un hecho dado, no es un destino fijo, no es el resultado de un programa rígido, sino un proceso cambiante con múltiples posibilidades de desarrollo. Los cuerpos de los hombres y los cuerpos de las mujeres no responden de manera unívoca a un patrón inalterable, sino que transcurren a lo largo de la vida por múltiples experiencias que van configurando cada cuerpo de manera única e irrepetible. Como dice Loïc Wacquant, refiriéndose a la experiencia de los boxeadores: "el cuerpo puede ser significativamente remodelado en términos de su volumen y su forma" (1999: 248-249).

Este modelado tiene diferentes desenlaces en función del momento en que comienza, teniendo en cuenta además los rasgos específicos de cada disposición fisiológica, psicológica y social; las condiciones del medio (clima, alimentación, distancias, instalaciones); las características particulares de cada deporte y cada programa de entrenamiento; la habilidad del entrenador o el apoyo moral, emocional, económico, que el atleta recibe de su entorno. O sea, una infinidad de detalles, cada uno en sí mismo crucial25.

"Los 'efectos superficiales' de las prácticas corporales y los micro-poderes borran el trabajo, el tiempo y las condiciones que vuelven estos cuerpos posibles y deseables" (Cole, 1993: 88). 
Para las feministas "de la sospecha", este moldeamiento y re-moldeamiento ocurre de manera negativa en los cuerpos de las mujeres. En este momento no nos detengamos en averiguar si esta negatividad es una acción deliberada y maligna del patriarcado para abatir las fuerzas de las mujeres; detengámonos solamente en sus resultados. Primero veamos el efecto "círculo vicioso": las mujeres no se desarrollan físicamente al parejo de los varones. En promedio, las niñas empiezan a participar en el deporte dos años más tarde que los niños, pero, además, según documenta Colette Dowling, en Estados Unidos las niñas abandonan el deporte organizado con seis veces más frecuencia que los niños. Como "el movimiento vigoroso y el uso expansivo del espacio están codificados como masculinos, las niñas los evitan" (2000: 53).

"Un estudio de las actividades en el campo de juego de aproximadamente 300 niños y niñas entre el primero y el cuarto grados encontró que los niños se dedican a juegos grandes, organizados por ellos mismos, como el béisbol, mientras que las niñas andan en grupitos de dos o tres, platicando (... ${ }^{26}$. Hay evidencia considerable la cual confirma que a las niñas a menudo se les estimula muy poco para el movimiento físico (...). Diferentes conjuntos de conductas de juego empiezan a evolucionar para varones y hembras en edades muy tempranas y primariamente bajo la dirección de progenitores y cuidadores (...). Desde antes de que las criaturas aprendan a hablar, ambos progenitores inducen conductas motoras en sus hijos de manera más intensa que en sus hijas" (Ibíd: 54-55).

El efecto "círculo vicioso" consiste en una retroalimentación de la ineptitud corporal sobre la evidencia de que "las mujeres son ineptas físicamente". Como los niños empiezan a practicar ejercicios motores de gran escala mucho más temprano que las niñas, éstas abandonan el campo en cuanto se dan cuenta de lo difícil que es para ellas todo lo que en los varones parece "natural". La dificultad se deriva de su escasa participación en el deporte y tiene como resultado inmediato una negativa a participar. En resumen, las niñas aprenden desde muy temprano en la vida que los deportes son "poco femeninos": "Mucha de la desaprobación y las críticas hacia las mujeres en deportes de contacto se originan en una noción equívoca de que la violencia es masculina y de que las mujeres que se comportan de maneras violentas son, de alguna manera, anti-naturales y anormales" (Lawler, 2002: 104).

El efecto concomitante del círculo vicioso, al cual denominaré "indefensión programada", tiene que ver con la renuncia activa de las mujeres al tipo de poder específicamente físico que radica en el cuerpo. En el imaginario social, la alternativa a que se ven enfrentadas las mujeres implica: o bien someterse a las normas occidentales de la belleza, que promueven la delgadez, la fragilidad y la vulnerabilidad como cualidades sexualmente deseables

26 The Melpomene Institute, una asociación dedicada a la investigación y la docencia, con base en St. Paul, llevó a cabo el estudio reportado por Mary Duffy en "Making workouts for the strengths of girls" (véase The New York Times, 13 de junio de 1999, p. A21). 
para las mujeres; o bien desarrollar sus cuerpos en busca de una forma de poderío que es minuciosamente resistido y combatido con el expediente de que es "poco femenino". Las mujeres son socializadas para encarnar "un vocabulario de limitación del movimiento como parte de su identidad femenina, uno que enfatiza la suavidad, la vulnerabilidad, la debilidad física y el miedo a lastimarse" (Castelnuovo y Guthrie, 1998: 68)²7.

Colette Dowling (Op. cit.) asegura que el mito de la fragilidad de las mujeres se toma como una verdad gracias a la intervención de una enorme cantidad de autoridades (médicos, educadores, líderes religiosos) que lo han hecho viable gracias a una serie de mecanismos sociales muy elaborados para "mantener a las mujeres apartadas de su fuerza" (6), para convertirlas en víctimas "y enseñarles que la victimización es lo único a lo que pueden aspirar" (Ibíd.).

Una de las instituciones más eficaces para implantar este tipo de tecnologías de género es la de los deportes organizados y definidos como coto masculino. En tanto se identifican como actividades apropiadas para los varones, los deportes ayudan a convertir las ficciones políticas del género en disposiciones femeninas específicas (o, en términos de Bourdieu, en sentido práctico). Estas disposiciones tienen un efecto en las relaciones entre los sexos que ha llevado a algunas feministas a sugerir la indefensión como un programa patriarcal:

"Si preguntas no por quélas mujeres y los hombres llevan a cabo diferentes actividades corporales, sino por qué la feminidad ha significado debilidad física, notas que alguien físicamente débil es más fácilmente violable, disponible para ser molestada, abierta al acoso sexual. Femenino significa violable" (MacKinnon, 1987: 118).

Dowling, Young y MacKinnon coinciden en que la exclusión del campo deportivo no es el único, y ni siquiera el más importante, de los mecanismos que el sistema de género utiliza para reducir la actividad corporal de las mujeres a su mínima expresión. Las tres autoras afirman que, al margen de ese universo, aprendemos a ser discapacitadas. Se nos impone una debilidad obligatoria, una falta de conexión entre cuerpo y espíritu en el ser y en el movimiento: "No es que los hombres sean entrenados para ser fuertes y las mujeres nada más no sean entrenadas. Los hombres son entrenados para ser fuertes y las mujeres son entrenadas para ser débiles" (Ibíd: 120).

Mackinnon nota que la mayor parte de las actividades atléticas han sido diseñadas para desarrollar y ampliar atributos idénticos a los que se valoran y premian como

$27 \quad$ Como afirman Castelnuovo y Guthrie (1998), "Ia construcción del sexo y el género en las sociedades occidentales requiere no sólo una ideología de la feminidad sino también la construcción física del cuerpo femenino, un proceso que ha involucrado prohibiciones contra el fortalecimiento físico y contra todas aquellas habilidades motrices y configuraciones corporales que permitan a las mujeres intimidar físicamente a los hombres" (36). Por otra parte, Judith Lorber (1993) asegura que "los deportes (...) construyen los cuerpos de los hombres para que sean poderosos; los cuerpos de las mujeres para que sean sexuales" (573). 
masculinos: Ios hombres, al aprender a ser hombres, "aprenden no sólo deportes, sino también aquellas cosas que se elevan, extienden, miden, evalúan y organizan en el deporte y como deporte" (Ibíd.). Entretanto, una mujer aprende que ser femenina significa ser pequeña, frágil, delgada, carente de musculatura; que para ser femenina tiene que exhibir esa discapacidad: dando pasos cortos, pidiendo ayuda para cargar cualquier cosa más o menos pesada, dependiendo de los varones para casi cualquier actividad que requiera cierta destreza corporal, como apretar un tornillo o cambiar una llanta. Desde diferentes experiencias, el feminismo "de la sospecha" reivindica la práctica femenina del deporte como una forma de "empoderamiento", en particular para resistir y oponerse a la denominada "cultura de la violación".

Desde este impulso, se opone a la ineptitud programada de las mujeres para las actividades físicas y, al mismo tiempo, al desprecio con que los varones se refieren a las hembras de la especie en diferentes contextos como organismos que están en desventaja física. No obstante, la cuestión sigue siendo un enigma: ¿logrará el feminismo alterar las modalidades de la existencia corpórea femenina? ¿Será posible echar a andar un programa social, un nuevo conjunto de tecnologías de género, para subvertir la situación de debilidad, fragilidad y vulnerabilidad de las mujeres?

\section{BIBLIOGRAFÍA}

Baz, Margarita (1996): Metáforas del cuerpo. Un estudio sobre la mujer y la danza, Programa Universitario de Estudios de Género de la UNAM. México: Miguel Ángel Porrúa.

Bernard, Michel (1994): El cuerpo. Un fenómeno ambivalente. Barcelona: Paidós.

Bordo, Susan (1993): Unbearable weight:feminism, western culture, and the body. Berkeley: University of California Press.

Bourdieu, Pierre (1991): El sentido práctico. Madrid: Taurus Humanidades.

(1996): "La dominación masculina”, en La ventana, No. 3, pp. 7-95.

(2000): La dominación masculina. Barcelona: Anagrama.

Buñuel Heras, Ana (1995): "La construcción social del cuerpo de la mujer en el deporte", en Revista Española de Investigación Social, No. 68 (octubre-diciembre), pp. 97-117.

Butler, Judith (1996): "Variaciones sobre sexo y género: Beauvoir, Wittig y Foucault", en Lamas, Marta (comp.): El género: la construcción cultural de la diferencia sexual, pp. 303-326. México: PUEG-UNAM.

(1998): "Actos perfomativos y constitución del género: un ensayo sobre fenomenología y teoría feminista", en debate feminista, Año 9, Vol. 18, octubre, pp. 296-314. 
- (2001): El género en disputa. El feminismo y la subversión de la identidad. México: Paidós.

- (2002): Cuerpos que importan. Sobre los límites materiales y discursivos del "sexo". Buenos Aires: Paidós.

- (2006): Deshacer el género. Barcelona: Paidós.

Castelnuovo, Shirley y Guthrie, Sharon (1998): Feminism and the female body. Liberating the amazon within. Boulder/Londres: Lynne Rienner.

Cole, Cheryl L. (1993):"Resisting the canon: feminist cultural studies, sport and technologies of the body", en Journal of Sport and Social Issues, agosto, Vol. 17, No. 2, pp. 77-97.

Connell, R. W. (2003): Masculinidades. México: PUEG-UNAM.

Crossley, Nick (1996): "Body-subject/body-power: agency, inscription and control in Foucault and Merleau-Ponty", en Body and Society 2(2), pp. 99-116.

(2001): The social body. Habit, identity and desire. Londres: Sage.

- (2004):"The circuit trainer's habitus: reflexive body techniques and the sociality of the workout", en Body and Society, Vol. 10, No. 3, pp. 37-69.

De Certeau, Michel (1996): La invención de lo cotidiano: 1. Artes de hacer. México: Universidad Iberoamericana, Instituto Tecnológico de Estudios Superiores de Occidente, Centro Francés de Estudios Mexicanos y Centroamericanos.

De Lauretis, Teresa (1987): Technologies of gender. Essays on theory, film, and fiction. Bloomington e Indianápolis: Indiana University Press.

--------- (2000):"La tecnología del género", en Diferencias. Etapas de un camino a través del feminismo, pp. 33-69. Madrid: Horas y horas.

Dowling, Colette (2000): The frailty myth. Women approaching physical equality. Nueva York: Random House.

Esteban, Mari Luz (2004): Antropología del cuerpo: género, itinerarios corporales, identidad y cambio. Barcelona: Ediciones Bellaterra.

Fausto-Sterling, Anne (2000): Sexing the body. Gender politics and the construction of sexuality. Nueva York: Basic Books. 
Fenstermaker, Sarah; West, Candace y Zimmerman, Don (2002): "Gender inequality: new conceptual terrain", en Fenstermaker y West: Doing gender, doing difference. Inequality, power, and institutional change. Nueva York: Routledge.

Fields, Sarah K. (2005): Female gladiators. Gender, law and contact sport in America. Urbana y Chicago: University of Illinois Press.

Foucault, Michel (1990): Tecnologías del yo y otros textos afines. Barcelona: Paidós. (2002): Defender la sociedad. México: Fondo de Cultura Económica.

Garfinkel, Harold (2006): Estudios en etnometodología. Barcelona: Anthropos / CEIICHUNAM / Universidad Nacional de Colombia.

Goffman, Erving (1959): The presentation of self in everyday life. Nueva York: Anchor Books. (1977): "The arrangement between the sexes", en Theory and Society, Vol. 4, No. 3, pp. 301-331.

Goldstein, Joshua (2002): "La correspondencia entre género y guerra”, en debate feminista: violencias, Año 13, Vol. 25, abril, pp. 115-130.

Grosz, Elizabeth (1994): Volatile bodies. Toward a corporeal feminism. Bloomington: Indiana University Press.

Hargreaves, Jennifer (1994): Sporting females. Critical issues in the history and sociology of women's sports. Londres y Nueva York: Routledge.

Kimmel, Michael (1987): "Men's responses to feminism at the turn of the century", en Gender and Society, Vol. 1, No. 3, septiembre, pp. 261-283.

Laqueur, Thomas (1994): La construcción del sexo. Cuerpo y género desde los griegos hasta Freud. Madrid: Ediciones Cátedra / Universitat de València / Instituto de la Mujer.

Lawler, Jennifer (2002): Punch! Why women participate in violent sports. Terre Haute, Indiana: Wish Publishing.

Lorber, Judith (1993): "Believing is seeing: biology as ideology", en Gender and Society, Vol. 7, No. 4, diciembre, pp. 568-581.

MacKinnon, Catherine (1987): "Women, self-possession and sport", en Feminism unmodified. Discourses on life and law, pp. 117-124. Cambridge: Harvard University Press. 
"Official Website of the Olympic Movement" (s.f.) [on line]. Disponible en: http://www. olympic.org/uk/games/past/index uk [Recuperado el 26 de noviembre de 2009]

Spelman, Elizabeth (1982): "Woman as body: ancient and contemporary views", en Feminist Studies, Vol. 8, No. 2, primavera, pp. 109-131.

Turner, Bryan (1989): El cuerpo y la sociedad. Exploraciones en teoría social. México: Fondo de Cultura Económica.

Vázquez, Francisco y Moreno, Andrés (1997): Sexo y razón. Una genealogía de la moral sexual en España (siglos XV1-Xx). Madrid: Akal Universitaria.

Vigarello, Georges (2005a): "Ejercitarse, jugar", en Corbin, Courtine y Vigarello: Historia del cuerpo, Vol. 1: Del Renacimiento a la llustración (dirigido por G. Vigarello), pp. 229-292. Madrid:Taurus.

(2005b): Historia de la belleza. El cuerpo y el arte de embellecer desde el Renacimiento hasta nuestros días. Buenos Aires: Nueva Visión.

(2005c): Corregir el cuerpo. Historia de un poder pedagógico. Buenos Aires: Nueva Visión.

Vigarello, Georges y Holt, Richard (2005):"El cuerpo cultivado: gimnastas y deportistas en el siglo xIx", en Corbin, Courtine y Vigarello: Historia del cuerpo, Vol. 2: De la Revolución Francesa a la Gran Guerra (dirigido por A. Corbin), pp. 295-354. Madrid:Taurus.

Wacquant, Loïc (1999):"Un arma sagrada. Los boxeadores profesionales: capital corporal y trabajo corporal", en Auyero, Javier: Caja de herramientas. El lugar de la cultura en la sociología norteamericana, pp. 237-292. Buenos Aires: Universidad Nacional de Quilmes.

West, Candace (1996): "Goffman in feminist perspective", en Sociological Perspectives, Vol. 39, No. 3, otoño, pp. 353-369.

West, Candace y Zimmerman, Don (1987): "Doing gender", en Gender and Society 1, pp. 125-151.

Young, Iris Marion (1990): "Throwing like a girl. A phenomenology of feminine body comportment, motility and spatiality", en Throwing like a girl and other essays in feminist philosophy and social theory, pp. 141-159. Bloomington e Indianápolis: Indiana University Press. 